\title{
Role of water on the structure of palladium for methane complete oxidation
}

\author{
Xiansheng Lia,b, Xing Wang ${ }^{a, b}$, Kanak Roy ${ }^{a}$, Jeroen A. van Bokhoven*,a,b, Luca Artiglia*,b,c \\ anstitute for Chemical and Bioengineering, Department of Chemistry and Applied Biosciences, \\ ETH Zurich, 8093 Zurich, Switzerland \\ bLaboratory for Catalysis and Sustainable Chemistry, Paul Scherrer Institut, 5232 Villigen, \\ Switzerland \\ 'Laboratory of Environmental Chemistry, Paul Scherrer Institut, 5232 Villigen, Switzerland
}

\begin{abstract}
Palladium-based catalysts are attractive for methane combustion on natural gas vehicles at low temperature. By means of ambient pressure x-ray photoelectron spectroscopy, we investigated the reaction on a palladium foil exposed to different mixtures at increasing temperature. Water affects the long-term catalyst stability and blocks the active sites, ascribed to the hydroxyl inhibition effect. We investigated such an effect both under steady state and under transient reaction conditions, to understand the mechanism of inhibition. The hydroxyl formation on the surface of palladium blocks the sites for methane activation, postponing the formation of the active palladium oxide phase in the bulk.
\end{abstract}

\section{Keywords}

Methane oxidation, palladium, water inhibiting, active sites, ambient pressure X-ray photoelectron spectroscopy (APXPS)

This document is the accepted manuscript version of the following article:

Li, X., Wang, X., Roy, K., van Bokhoven, J. A., \& Artiglia, L. (2020). Role of water on the structure of palladium for methane complete oxidation. ACS Catalysis. https:// doi .org/10.1021/acscatal.0c01069 


\section{Introduction}

Natural gas has enormous potential as an alternative to traditional automotive fuels, because of its high energy density and low emission of gaseous pollutants ${ }^{1-2}$. Lean-burning natural gas vehicles (NGVs) have higher fuel combustion efficiencies and minimize emissions of incomplete combustion products such as carbon monoxide and volatile organic compounds 3 . However, the fraction of unburned methane in the exhaust gas poses a great potential threat to the environment due to its strong greenhouse effect ${ }^{4}$. Complete methane oxidation is the main treatment technology in a NGV, however it is challenging due to the following reasons: (i)strong carbon to hydrogen bond ${ }^{5}$, (ii)low exhaust gas temperature of $\mathrm{NGVs}^{6-7}$ and (iii)high concentration of water in the exhaust gas ${ }^{8-10}$.

Palladium-based catalysts are the most-active for methane complete oxidation and have been extensively investigated ${ }^{8,11-16}$. It is now generally agreed that palladium oxide is the key active phase for the exceptional performance of supported palladium catalysts ${ }^{6,8,14}$. However, open questions remain, such as what is or are the role(s) of bulk vs surface palladium oxide and how does water inhibit the reaction ${ }^{3}, 15,17-20$. Bruch $^{21}$ reported that the fully oxidized palladium (II) oxide is the optimum phase for methane oxidation and the intermediate state corresponding to a 'skin' of palladium oxide (surface palladium oxide) on a palladium metal core has lower activity. Fujimoto et al. ${ }^{14}$ proposed that $\mathrm{C}-\mathrm{H}$ bond activation takes place on a surface active site pair consisting of oxygen atoms and coordinatively unsaturated palladium sites. Methane from the gas phase adsorbs on the latter, while neighboring oxygen atoms extract protons from it forming hydroxyl groups. Such palladium active sites were introduced into the reaction sequence by postulating the presence of oxygen vacancies; oxygen vacancies are regenerated at the end of a catalytic cycle by recombination of surface hydroxyl groups 
formed in $\mathrm{C}-\mathrm{H}$ bond activation steps, which allows explaining the negative reaction order of water (equation 1). Recently, $\mathrm{PdO}_{\mathrm{x}}$ and $\mathrm{Pd}-\mathrm{PdO}_{\mathrm{x}}$ structures were also found on $\mathrm{Al}_{2} \mathrm{O}_{3^{-}}$ decorated $\mathrm{Pd} / \mathrm{SiO}_{2}$ catalysts synthesized by means of atomic layer deposition ${ }^{22}$.

In practical applications, water significantly suppresses the activity of palladium catalysts at lower temperatures. As described in the methane oxidation kinetic rate equation,

$r=k\left(\mathrm{CH}_{4}\right)^{0.7}\left(\mathrm{O}_{2}\right)^{0.2}\left(\mathrm{H}_{2} \mathrm{O}\right)^{-0.9}$,

methane oxidation rates (calculated over a palladium foil) are inversely proportional to the concentration of water, whether water is generated during reaction or is introduced to the reaction gas mixture. The same reaction kinetic rate equation has also been evaluated on supported palladium nanoparticles catalysts, and the reaction order of water ranged from 0.9 to $-1.1^{13-14,23}$.

So far, there have been different interpretations of the inhibitory effects of water on methane oxidation, and a clear explanation of it is still missing ${ }^{6,10,24-26}$. It was initially reported that the formation of stable and inactive surface hydroxide, $\mathrm{Pd}(\mathrm{OH})_{2}$, inhibited and deactivated supported palladium catalysts ${ }^{8,12}$. Recently, Barrett et al. observerd palladium hydroxide phase formation by means of in situ x-ray absorption spectroscopy (XAS) over $\mathrm{Pd} / \mathrm{Al}_{2} \mathrm{O}_{3}$ catalyst ${ }^{27}$. They also showed that water inhibits the oxidation of metallic palladium, which is supported by temperature programmed oxidation (TPO) experiments ${ }^{28}$ and electron microscopy ${ }^{29}$. However, several researchers claimed that the water inhibition is due to coverage effects, rather than structural and/or phase changes ${ }^{20,30}$. The hydroxylation of the support and especially of palladium oxide by water dissociation was observed in situ by means of DRIFTS ${ }^{31}$, and was further confirmed by other literature reports ${ }^{10,14,26,32}$. The occupation 
of coordinatively unsaturated palladium sites by water/hydroxyls is likely to inhibit methane activation on palladium oxide ${ }^{24}$. A considerable number of papers have demonstrated that the addition of platinum to a palladium catalyst increases the methane oxidation activity, especially under wet feed conditions. ${ }^{33-35}$ Platinum was proposed to provide new sites for methane dissociation when palladium sites are blocked by water ${ }^{34}$. Additionally, suppression of oxygen exchange $\mathrm{e}^{26,28,36}$ was also considered as the water inhibition effect.

In general, the disagreement on the water inhibition effect in the combustion of methane could be partially assigned to the complexity of the investigated catalytic systems. The particle size, support interaction, crystal structure and activation strategy could affect the catalytic process, thus the state and behavior of active sites ${ }^{37}$. However, limited by the inability to directly observe oxygen and palladium at the same time, the role and behavior of surface water species for palladium species is not directly supported by experimental methods. A suitable approach would envisage the characterization of the catalyst-reactant mixture (solidgas) interface performed in situ. The approach proposed in the present study was to use a model system to study particular aspects of the catalytic combustion chemistry of methane on palladium catalysts. Spectroscopic methods are particularly useful to investigate catalytic systems under in situ and operando conditions ${ }^{38-40}$. The possibility of working under reactionrelevant conditions while acquiring the spectroscopic fingerprint or the species involved has helped to identify more in depth previously unknown reaction mechanisms and to develop novel materials. Among all the in situ spectroscopic methods, ambient pressure x-ray photoelectron spectroscopy (APXPS) stands out for its surface sensitivity, which allows the direct characterization of relevant interfaces, such as the solid-gas, the liquid-vapor and the solid-liquid ${ }^{41-46}$. In this study, we employed in situ XPS to detect the structural development 
of palladium catalysts during the oxidation of methane and to study the influence of water. Based on the experimental results, we propose that hydroxyl accumulation on the surface of palladium hinders the catalytic combustion reaction by occupying the coordinatively unsaturated palladium sites and the neighbor oxidic sites, which are the methane adsorption and activation sites. Moreover, such inhibition effect also hinders oxygen activation and mobility, preventing the formation of the bulk palladium oxide. 


\section{Experimental Methods}

The experiments were carried out at the X07DB In Situ Spectroscopy beamline of the Swiss Light Source synchrotron. The solid-gas interface endstation, connected to a differentially pumped Scienta R4000 HiPP-2 electron analyzer, allows the manipulation of solid samples while dosing a gas/gas mixture in the mbar range. Thanks to the small volume of the experimental cell, both steady state experiments and transient state experiments are possible $^{47}$. In the former case, a gas/gas mixture flows in the experimental cell at a stable pressure and the spectra are acquired summing up several sweeps of the same kinetic energy region. In the latter case, fast switches (in timescale of seconds) between gas mixtures are realized while the evolution of a spectral line is followed in fast-scan mode (time resolution down to the second range ${ }^{43}$ ). In this study, the $P d 3 d_{5 / 2}$ peak was acquired in snapshot mode, that is, setting the kinetic energy of the analyzer on the centroid of a peak. The kinetic energy window is approximately $1 / 10$ of the selected analyzer pass energy ( $50 \mathrm{eV}$ in this study), thus $5 \mathrm{eV}$ in this case (+-2.5 eV with respect to the kinetic energy setpoint). A single spectrum of the $\mathrm{Pd} 3 \mathrm{~d}_{5 / 2}$ was acquired with a total time resolution of $1.8 \mathrm{sec}$. Fast gas switches are possible thanks to the flow tube configuration of the cell, where the gas flow can be properly tuned setting the flow rates from mass flow controllers and stabilizing the pressure by means of a diaphragm valve coupled to a root pump downstream. Linearly polarized light was used throughout the experiments.

Palladium foils (99.99\% purity, $0.5 \mathrm{~mm}$ thickness) were obtained commercially. A $10 \times 10 \mathrm{~mm}$ foil was fixed to the manipulator head by means of copper clips. The temperature was monitored with a Pt100 sensor, and the sample was heated by means of a tunable power IR laser (976 nm, maximum power $25 \mathrm{~W}$ ) projected on the back side of the sample holder. In the 
geometry adopted during the experiments, photoelectrons were detected at an angle of $30^{\circ}$ with respect to the direction of the surface normal.

The as-introduced foil was heated in oxygen ( $1 \mathrm{mbar}$ ) at $650^{\circ} \mathrm{C}$ to remove surface carbon contamination, then oxygen was replaced by helium while keeping the temperature stable at $650^{\circ} \mathrm{C}$, to fully reduce the sample before starting the experiment. The photoemission spectra of $\mathrm{Pd} 3 \mathrm{~d}$ and $\mathrm{Pd} 3 \mathrm{p} / \mathrm{O}$ 1s were collected in $\mathrm{CH}_{4}+\mathrm{He}$ and then switching to $\mathrm{CH}_{4}+\mathrm{O}_{2}$ at different temperature steps in the $50-600^{\circ} \mathrm{C}$ range. The mixture of $\mathrm{CH}_{4}+\mathrm{He}$ was also replaced by pure $\mathrm{O}_{2}$ or $\mathrm{CH}_{4}+\mathrm{O}_{2}+\mathrm{H}_{2} \mathrm{O}$ while measuring XPS. Following this procedure, the oxidation state of palladium at different reaction temperatures and gas mixtures could be followed in situ. An annealing of the sample at $650^{\circ} \mathrm{C}$ in helium was performed after each reaction step, in order to fully reduce the surface and to always start measuring on the same sample surface. The cleanness and electronic state of palladium was checked by means of XPS (C 1s photoemission signal and wide range scan) after each reaction step, to sort out the accumulation of soot.

The experiments were performed at 1 mbar pressure in different $\mathrm{CH}_{4} / \mathrm{O}_{2}$ ratios (1:2 and 1:4), in pure oxygen and co-feeding water in the reaction mixture to check its effect on the reactivity $\left(1: 4=\mathrm{CH}_{4}: \mathrm{O}_{2}\right.$ molar ratio $+5 \% \mathrm{H}_{2} \mathrm{O}$, based on the partial pressures detected in the experimental cell). Ultrapure gases were used throughout the experiments and water vapor was generated from a thermalized reservoir containing Millipore water purified by means of several freeze-pump-thaw cycles. During transient experiments, oxygen was quickly replaced by helium (in the second range) while keeping the pressure in the cell constant at $1 \mathrm{mbar}$ and while acquiring the $P d 3 d_{5 / 2}$ core level peak in snapshot mode.

The Pd 3d and O 1s/Pd 3p spectral regions were recorded using excitation energies of $630 \mathrm{eV}$ and $825 \mathrm{eV}$, respectively, to collect photoelectrons with approximately the same kinetic 
energy of $300 \mathrm{eV}$, thus generated from the same probed depth. After subtraction of a Shirley background, the photoemission peaks were deconvoluted using Voigt shaped functions. Asymmetric Doniach-Sunjic ${ }^{48}$ line shape was used to fit the metallic palladium component of the $\mathrm{Pd} 3 \mathrm{~d}$ peaks, in agreement with previous literature reports ${ }^{49-52}$. The position (binding energy scale), full width at half maximum (FWHM) and the line-shapes were constrained during the deconvolution of peak components associated with the same oxidation state. The fitting parameters are listed in Table 1 . The error associated to the area of different components obtained from the deconvolution of the Pd 3d signal is the standard deviation calculated repeating the fitting on a statistically relevant sample of spectra collected under the same reaction conditions.

Table 1 Peak fitting parameters (position and FWHM) of Pd 3d and $\mathrm{O} 1$ s photoemission spectra

\begin{tabular}{cccc}
\hline \multicolumn{2}{c}{ Components } & Position $(\mathrm{eV})$ & FWHM $(\mathrm{eV})$ \\
\hline \multirow{3}{*}{$\mathrm{Pd}$ 3d } & $\mathrm{Pd}(0)$ & 335.95 & 0.6 \\
& $\mathrm{PdO}_{\mathrm{x}}$ & 335.6 & 1.9 \\
& $\mathrm{PdO}$ & 336.7 & 0.9 \\
\hline \multirow{3}{*}{$\mathrm{O} 1 \mathrm{~s}$} & $\mathrm{O}(1)$ & 529.3 & 1.3 \\
& $\mathrm{O}(2)$ & 530.2 & 1.3 \\
& $\mathrm{Pd}-\mathrm{OH}$ & 531.6 & 1.3 \\
\hline
\end{tabular}




\section{Results}

Figure 1 shows the $\mathrm{Pd} 3 \mathrm{~d}$ spectra measured at 1 mbar in pure oxygen, in a mixture of methane and oxygen in ratios of $1: 4$ and $1: 2$, and in a mixture of methane and oxygen in a ratio of $1: 4$, co-fed with $5 \% \mathrm{H}_{2} \mathrm{O}$. The spectra were collected at increasing temperature in the $50^{\circ} \mathrm{C}-600^{\circ} \mathrm{C}$ range. The red spectra correspond to the reference metal palladium signal, acquired at $50^{\circ} \mathrm{C}$ immediately after sample cleaning, and are normalized to the maximum intensities and superimposed to the spectra acquired in the low reaction temperature range $\left(150^{\circ} \mathrm{C}-300^{\circ} \mathrm{C}\right)$ to highlight the evolution of the peak line shape. In addition, an example of a deconvolution of a $\mathrm{Pd} 3 \mathrm{~d}_{5 / 2}$ core level peak is displayed in Figure $1(\mathrm{e})$. The $\mathrm{Pd} 3 \mathrm{~d}_{5 / 2}$ line can be deconvoluted into three components ${ }^{49-51,53:}$ the metal component at $334.95 \mathrm{eV}$ and two oxidic ones shifted towards higher binding energy by 0.65 and $1.7 \mathrm{eV}$, respectively. Palladium foil exhibits a typical oxidation process from palladium metal (334.95 eV), to a "surface palladium oxide" (335.6 eV), and then to "bulk palladium(II) oxide" $(336.7 \mathrm{eV})^{53-54}$. The twodimensional surface palladium oxide formed on the surface of $\mathrm{Pd}(111)$, was reported to be located at $+0.5-+1.3 \mathrm{eV}$ from the metal, ${ }^{50-51,53}$ and its structure was well characterized by LEED and $\mathrm{STM}^{53,55}$. In our experiments, we made use of a polycrystalline foil, thus surface palladium oxide formed on several different crystal facets. Due to the relatively small chamical shifts, all these contributions were convoluted in a single "surface oxide" component, whose full width at half maximum (FWHM) is larger than that of the other components ${ }^{56}$. In this paper, we denote metallic palladium as $\mathrm{Pd}(0)$, surface palladium oxide as "surface $\mathrm{PdO}_{\mathrm{x}}$ " and bulk palladium(II) oxide as " $\mathrm{PdO}$ ". At $50^{\circ} \mathrm{C}$, only $\mathrm{Pd}(0)$ can be detected. In the absence of water, a shoulder of the main peak, which is assigned to surface $\mathrm{PdO}_{\mathrm{x}}$, appears at $335.6 \mathrm{eV}$ and grows with temperature increasing to 150 and $200^{\circ} \mathrm{C}$. At higher temperatures $\mathrm{PdO}$, centered at $336.6 \mathrm{eV}$, gradually becomes the dominant species. When the temperature reaches $550^{\circ} \mathrm{C}$ 
and $600^{\circ} \mathrm{C}$, all palladium oxides are fully reduced to $\mathrm{Pd}(0)$. In the presence of water, the formation of surface $\mathrm{PdO}_{\mathrm{x}}$ also starts at $150^{\circ} \mathrm{C}$, and reaches its maximum value between 150 and $300^{\circ} \mathrm{C}$. The peak corresponding to $\mathrm{PdO}$ appears only at $350^{\circ} \mathrm{C}$, which is $100^{\circ} \mathrm{C}$ higher than in the water-free methane oxygen mixture at ratio $1: 4$. Also, in the presence of water, no quantitative reduction of the palladium oxide species happens even at $600{ }^{\circ} \mathrm{C}$.
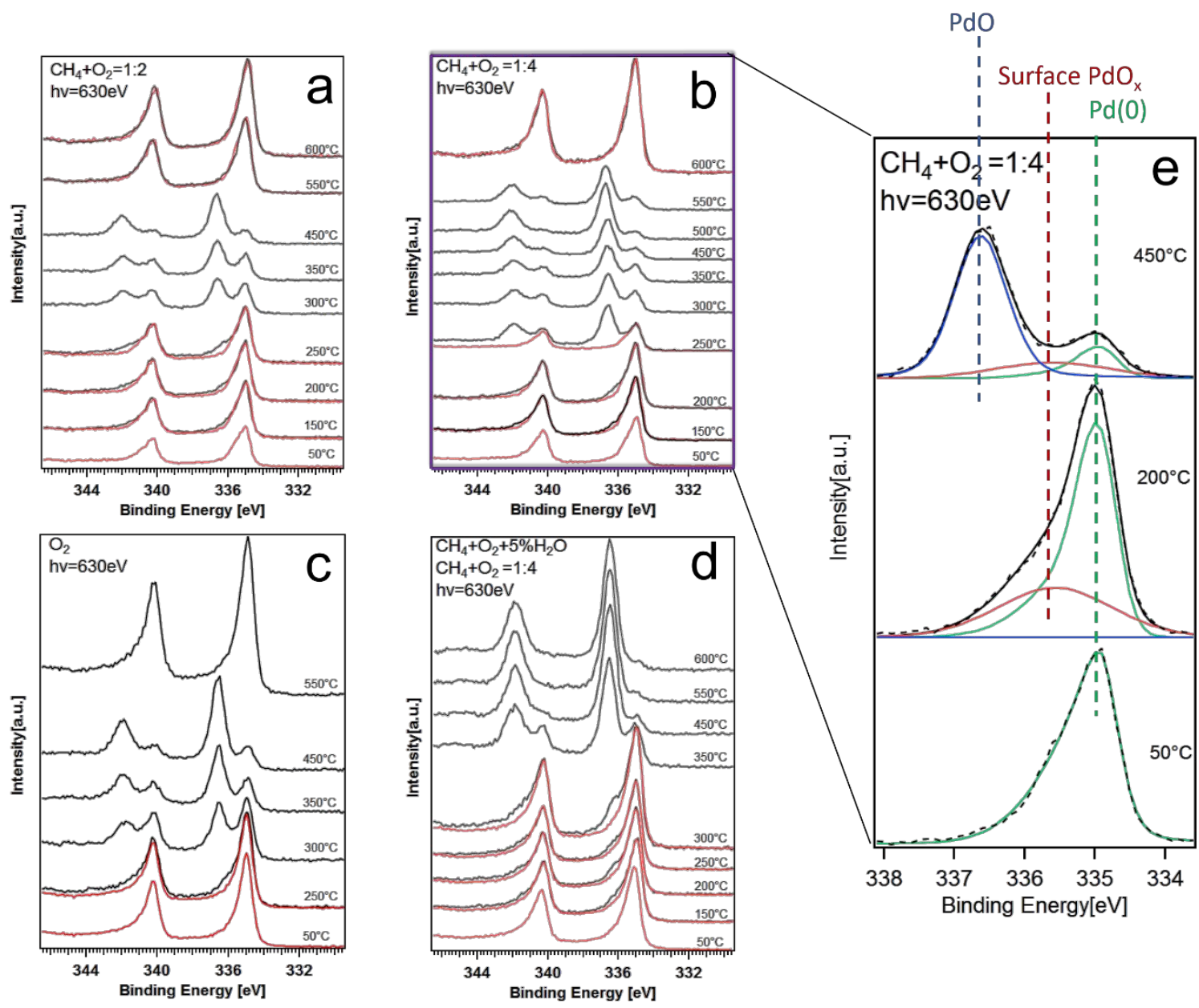

Figure 1 Steady state $\mathrm{Pd} 3 \mathrm{~d}$ photoemission spectra in gas atmosphere of (a) $\mathrm{CH}_{4}+\mathrm{O}_{2}=1: 2,(b) \mathrm{CH}_{4}+\mathrm{O}_{2}=1: 4$, (c) $\mathrm{O}_{2}$ only , (d) $\mathrm{CH}_{4}+\mathrm{O}_{2}+5 \% \mathrm{H}_{2} \mathrm{O}, \mathrm{CH}_{4}+\mathrm{O}_{2}=1: 4$ at different temperatures and (e) deconvolution of $\mathrm{Pd} 3 \mathrm{~d}_{5 / 2}$ spectra

Figure 2 shows the fraction of each palladium species at different temperatures and in different gas feed environments, evaluated from the deconvolution of the $\mathrm{Pd} 3 \mathrm{~d}_{5 / 2}$ spectra of Figure 1. In the first stage, in all the investigated gas compositions, $\mathrm{Pd}(0)$ converts into surface 
$\mathrm{PdO}_{\mathrm{x}}$. With increasing temperature $\left(>300^{\circ} \mathrm{C}\right)$, the percentages of both surface $\mathrm{PdO}_{\mathrm{x}}$ and $\mathrm{Pd}(0)$ decrease, whereas that of $\mathrm{PdO}$ increases and becomes the highest. The onset of surface $\mathrm{PdO}_{\mathrm{x}}$ growth is similar in all the investigated reaction environments, starting at $100^{\circ} \mathrm{C}$, whereas the evolution of $\mathrm{PdO}$ shows variation depending on the gas environment. $\mathrm{A} 50^{\circ} \mathrm{C}$ delay compared to the reaction mixture (methane + oxygen) is observed when only oxygen is dosed. Such a delay could be caused by the formation of an oxide skin in the presence of only oxygen, which could protect the metal from being further oxidized ${ }^{57}$. When methane is co-dosed in the reaction mixture, it reacts with the protection layer, and the formation of bulk oxide starts at lower temperature. The shift increases to $100^{\circ} \mathrm{C}$ when water is co-fed. The decreased oxidation to bulk PdO in the presence of water suggests either the hindrance of oxygen activation and of its diffusion ${ }^{26}$. Interestingly, the interval of stability of surface $\mathrm{PdO}_{\mathrm{x}}$ with the temperature is larger (from 100 to $300^{\circ} \mathrm{C}$ ) when water is co-dosed. For different $\mathrm{CH}_{4} / \mathrm{O}_{2}$ ratios, there is a subtle change in the onset of growth of PdO. This could be due either to a morphological change of the foil in the presence of methane, or to a different amount of water generated at different $\mathrm{CH}_{4} / \mathrm{O}_{2}$ ratios. At $600^{\circ} \mathrm{C}$, the highest investigated reaction temperature, all the palladium oxide species are reduced back to $\mathrm{Pd}(0)$, except in the case when water is co-dosed in the reaction mixture. 

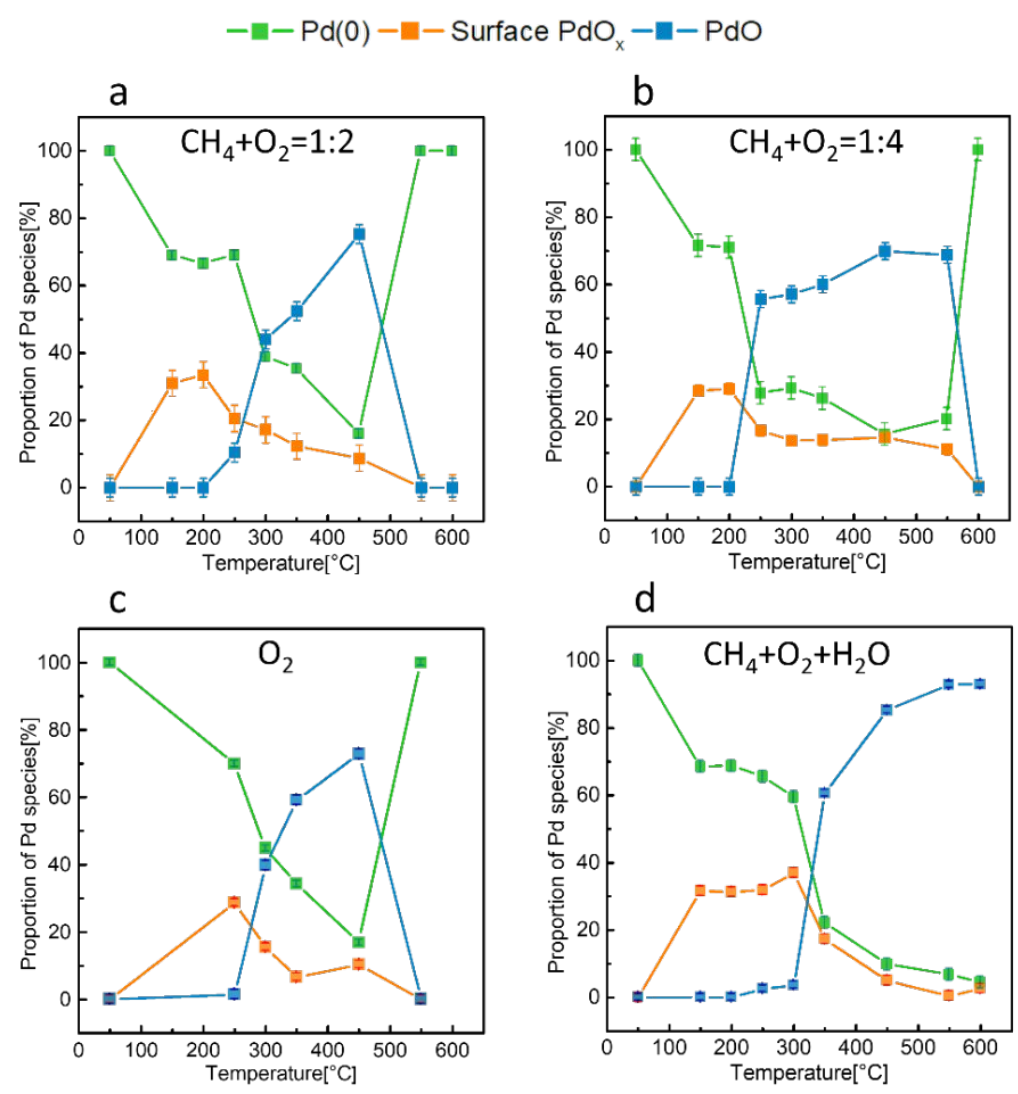

Figure 2 Proportion of $\mathrm{Pd}(0)$, surface $\mathrm{PdO}_{x}$ and $\mathrm{PdO}$ in gas atmosphere of (a) $\mathrm{CH}_{4}+\mathrm{O}_{2}=1: 2,(\mathrm{~b}) \mathrm{CH}_{4}+\mathrm{O}_{2}=1: 4$, (c) $\mathrm{O}_{2}$ only, (d) $\mathrm{CH}_{4}+\mathrm{O}_{2}+5 \% \mathrm{H}_{2} \mathrm{O}, \mathrm{CH}_{4}+\mathrm{O}_{2}=1: 4$ at different temperatures

Surface hydroxyls are expected to form on the surface of palladium foil both during the reaction (hydrogen abstraction from adsorbed methyl groups) and when water is co-dosed ${ }^{14}$, 58. However, the peak of surface palladium hydroxyls $(\mathrm{Pd}-\mathrm{OH})$ is reported to overlap with the surface $\mathrm{PdO}_{x}$ in the $\mathrm{Pd} 3 \mathrm{~d}$ photoemission spectra ${ }^{59}$. To elucidate the effect of water dosing during the methane oxidation reaction, and to monitor the amount surface hydroxyls, we also acquired the $\mathrm{Pd} 3 \mathrm{p}_{3 / 2} / \mathrm{O}$ 1s photoemission spectral region exposing the sample to a $1: 4$ methane + oxygen reaction mixture with and without co-dosing water (Figure 3 (a)). A temperature of $450^{\circ} \mathrm{C}$ was selected because in both cases the amount of $\mathrm{PdO}$ reaches its maximum. Figure $3(\mathrm{~b})$ displays the deconvolution of the $\mathrm{Pd} 3 \mathrm{p}_{3 / 2}$ and of the $\mathrm{O} 1 \mathrm{~s}$ 
photoemission peaks, which appear in a similar binding energy range. In the $\mathrm{Pd} 3 \mathrm{p}_{3 / 2}$ region, we fixed the surface $\mathrm{PdO}_{\mathrm{x}} / \mathrm{PdO}$ ratio to 0.21 and 0.058 for water-free and water-dosed samples, respectively, which is consistent with the ratios extrapolated from the deconvolution of the $\mathrm{Pd} 3 \mathrm{~d}$. As reported in reference ${ }^{55}$, the $\mathrm{O} 1$ s peaks centered at 528.8 and $529.6 \mathrm{eV}$ are assigned to surface palladium oxide. Therefore, in our experiment the low-BE peak, i.e. O(1), at $529.3 \mathrm{eV}$, corresponds to the topmost layer oxygen of surface $\mathrm{PdO}_{\mathrm{x}}$ whereas $\mathrm{O}(2)$ at $530.2 \mathrm{eV}$ is assigned to bulk $\mathrm{PdO}^{55-56}$. The third component, centered at $531.6 \mathrm{eV}$, can be clearly observed in both reaction environments and particularly in the presence of water. The peak can be assigned to palladium-coordinated hydroxyl groups $(\mathrm{Pd}-\mathrm{OH})^{59-60}$, which form both during the methane oxidation reaction and by reaction with water (when dosed in the feed). We calculate and list the oxygen species proportion under water/water-free conditions in Table 2. The concentration of $\mathrm{O}(1)$ reduces by $6 \%$, passing from $11 \%$ to $5 \%$, while the fraction of surface hydroxyls increases by 3.5 times, passing from $4 \%$ to $14 \%$. The fraction of $\mathrm{O}(2)$ is relatively constant.
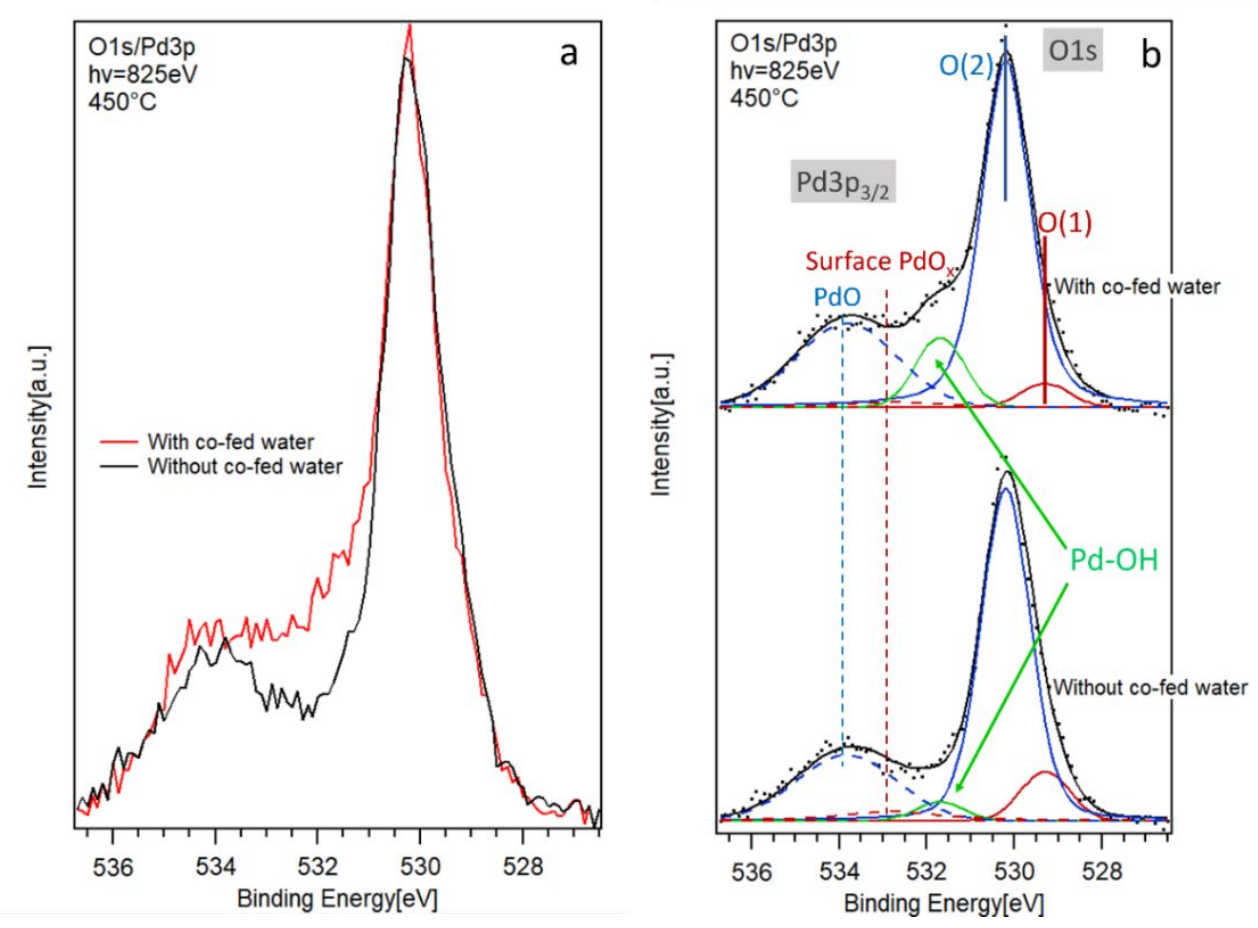
Figure 3 (a)Photoemission spectra of $\mathrm{O} 1 \mathrm{~s}$ and $\mathrm{Pd} 3 \mathrm{p}_{3 / 2}$ in the reaction gas of $\mathrm{CH}_{4}+\mathrm{O}_{2}$ and $\mathrm{CH}_{4}+\mathrm{O}_{2}+5 \% \mathrm{H}_{2} \mathrm{O}$ and (b) deconvolution of the spectra at $450^{\circ} \mathrm{C}$.

Table 2 Proportion of oxygen species in the reaction gas of $\mathrm{CH}_{4}+\mathrm{O}_{2}$ and $\mathrm{CH}_{4}+\mathrm{O}_{2}+5 \% \mathrm{H}_{2} \mathrm{O}$ at $450^{\circ} \mathrm{C}$. Calculated from $\mathrm{O}$ 1s deconvolution results.

\begin{tabular}{ccc}
\hline O 1s species & $\begin{array}{c}\text { Oxygen species proportion (\%) } \\
\text { without water }\end{array}$ & $\begin{array}{c}\text { Oxygen species proportion (\%) } \\
\text { with water }\end{array}$ \\
\hline $\mathrm{O}(1)$ & $11.3 \pm 0.6$ & $4.7 \pm 0.6$ \\
$\mathrm{O}(2)$ & $84.4 \pm 0.6$ & $81.5 \pm 1.8$ \\
$-\mathrm{OH}$ & $4.3 \pm 0.4$ & $13.8 \pm 1.7$ \\
\hline
\end{tabular}

We also compared the evolution of palladium species by means of time-resolved experiments performed under transient conditions, to characterize the formation process of the palladium oxides. The reaction environment was modified switching from a mixture not containing the oxidant $\left(\mathrm{CH}_{4}+\mathrm{He}\right)$ to one containing it $\left(\mathrm{CH}_{4}+\mathrm{O}_{2}\right.$ respectively $\left.\mathrm{CH}_{4}+\mathrm{O}_{2}+\mathrm{H}_{2} \mathrm{O}\right)$ while acquiring snapshots of the $P d 3 d_{5 / 2}$ spectrum (as reported in the experimental methods section). As an example, Figure 4 shows a series of snapshots of the $\mathrm{Pd} 3 \mathrm{~d}_{5 / 2}$ signal collected while switching from $\mathrm{CH}_{4}+\mathrm{He}$ to $\mathrm{CH}_{4}+\mathrm{O}_{2}(1: 4)$ at $450^{\circ} \mathrm{C}$. The color scale in figure $4(\mathrm{a})$ indicates the peaks location (bright regions) and their development as a function of time (1 iteration corresponds to 1 snapshot of the $P d 3 d_{5 / 2}$, thus to 1.8 seconds). Because no clear modifications of the $P d$ $3 d_{5 / 2}$ were evident comparing single snapshots, we summed up 20 consecutive iterations (corresponding to a time resolution of 36 seconds). As expected, the palladium foil was quickly oxidized after replacing helium with oxygen, and the evolution of the line shape of the spectra is shown in Figure 4(b). 


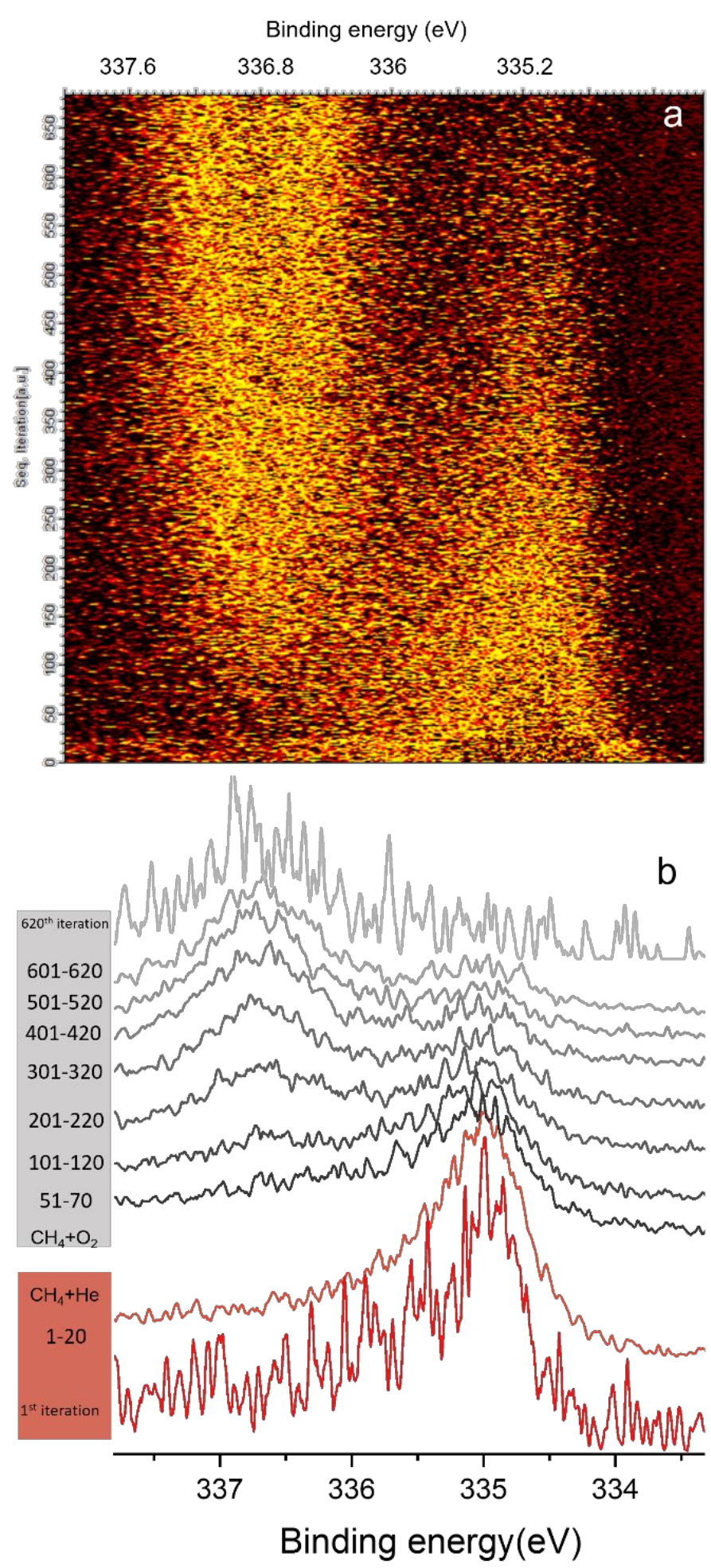

Figure 4 Evolution of (a) Pd $3 d_{5 / 2}$ spectra and (b) dimension-reduced Pd $3 d_{5 / 2}$ spectra after switching from $\mathrm{CH}_{4}+\mathrm{He}$ to $\mathrm{CH}_{4}+\mathrm{O}_{2}$ at $450^{\circ} \mathrm{C}$. The plot shows (for comparison) single snapshots ( $1^{\text {st }}$ and $620^{\text {th }}$ iteration) and the sum of 20 iterations (used for the deconvolution process and for the analysis of the time-evolution of the palladium species) collected under both reaction conditions. 
The summed spectra were deconvoluted using the parameters obtained from the analysis of the high resolution spectra (Table 1 and Figure $1(\mathrm{e})$ ) and the percentage of each single component is plotted as a function of time in Figure 5. All the plots show a common behavior: after a transient period, whose duration depends on the reaction environment and on the temperature and during which the percentage of the components varies sensibly, a plateau is reached, which corresponds to the steady-state conditions. The decrease of $\operatorname{Pd}(0)$ and the increase of surface $\mathrm{PdO}_{\mathrm{x}}$ and of $\mathrm{PdO}$ indicates the gradual oxidation of the palladium foil when it is exposed to the methane oxidation reaction mixture. The initial formation rate of surface $\mathrm{PdO}_{\mathrm{x}}$ is always higher or at least equal to that of $\mathrm{PdO}$, which implies that surface $\mathrm{PdO}_{\mathrm{x}}$ is the precursor of lattice $\mathrm{PdO}$. More importantly, the initial formation of surface $\mathrm{PdO}_{\mathrm{x}}$ and that of PdO display a slow-fast-slow process with temperature, visible in both reaction mixtures (Figure $5 \mathrm{a}$ and $5 \mathrm{~b}$ and Table 2). The fastest initial formation rate of $\mathrm{PdO}$ and of surface $\mathrm{PdO}_{\mathrm{x}}$ detected while dosing a $\mathrm{CH}_{4}+\mathrm{O}_{2}(1: 4)$ mixture is found at $350^{\circ} \mathrm{C}$. In the presence of water, the fastest initial formation rate of $\mathrm{PdO}$ and of surface $\mathrm{PdO}_{\mathrm{x}}$ shifts to $450^{\circ} \mathrm{C}$. Therefore, the addition of water to a methane combustion reaction mixture causes a positive shifts of the temperature at which the fastest oxidation of palladium takes place. Such a temperature shift correlates well with the analysis of the palladium species as a function of the reaction temperature discussed above (Figure 2). The evolution of the palladium species at $600^{\circ} \mathrm{C}$ in Figure 5 is also in agreement with the steady state results of Figure 2, i.e. no PdO formation is observed in the absence of water, whereas a gradual oxidation still takes place when water is co-dosed. 

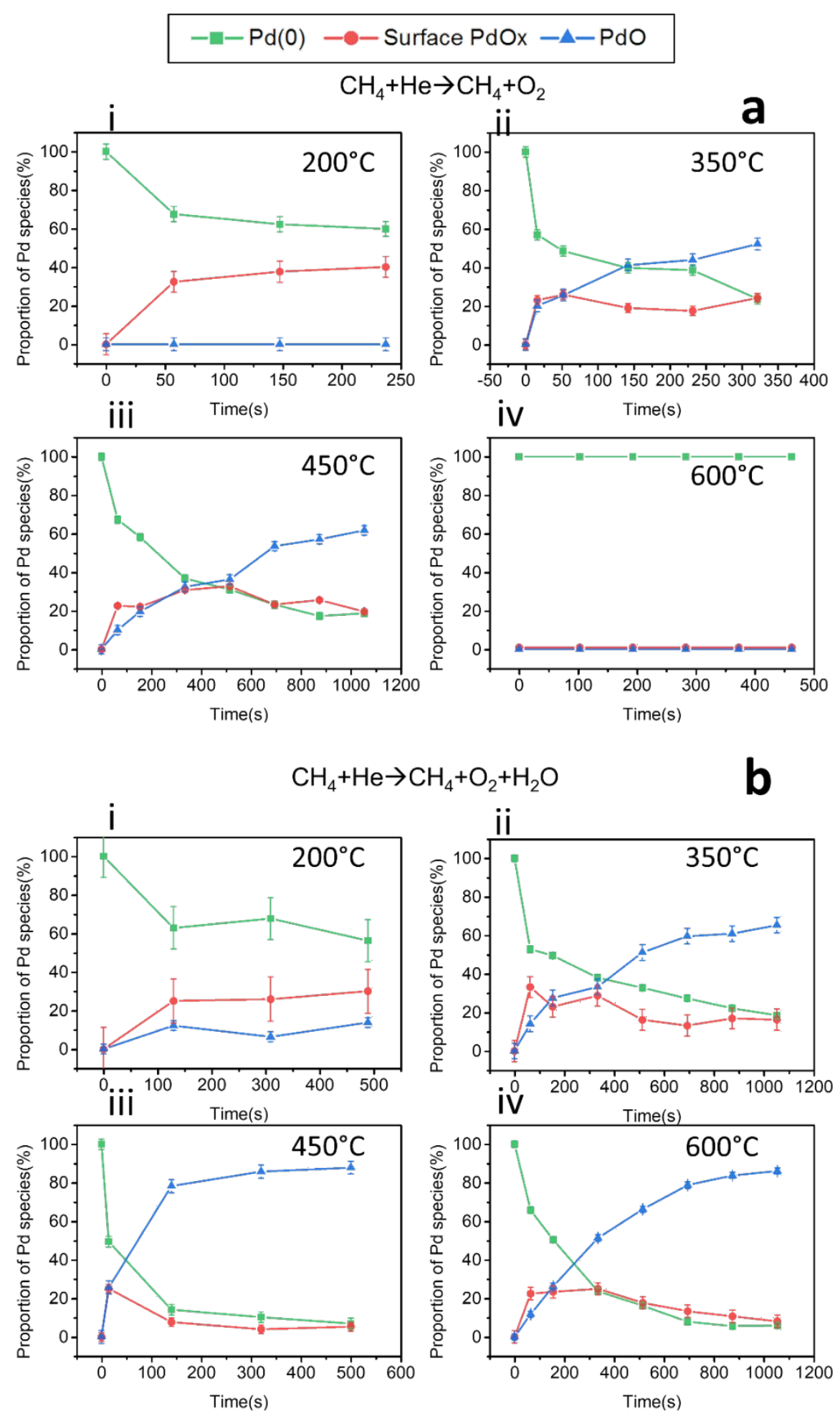

Figure 5 Time-resolved evolution of palladium species after switching from (a) $\mathrm{CH}_{4}+\mathrm{He}$ to $\mathrm{CH}_{4}+\mathrm{O}_{2}$ and (b) $\mathrm{CH}_{4}+\mathrm{He}$ to $\mathrm{CH}_{4}+\mathrm{O}_{2}+5 \% \mathrm{H}_{2} \mathrm{O}$ 


\section{Discussion}

Our main goal was to determine the influence of water on the structure of palladium catalyst for methane combustion. The interactions between the reagents and the catalyst surface in the absence and in the presence of water are important to follow the reaction mechanism and to identify the active sites involved.

It is commonly accepted that the addition of water causes a decrease of the catalytic activity of palladium catalysts. Kinetics results about methane combustion reaction over palladium model catalyst ${ }^{2,23}$ and nano-scale catalyst ${ }^{14}$ reported similar reaction order for water, ranging from -0.9 to -1.1 . This means that water has inhibition effect on both Pd foil and on supported Pd catalysts. To explain such an effect, it has been postulated that water blocks palladium active sites, forming either palladium hydroxide ${ }^{8,58}$ or surface hydroxyls ${ }^{14,26}$.

The formation of hydroxyl groups detected in Figure 3 supports the assumption that the palladium active sites are blocked by hydroxyls. Surface palladium hydroxyl groups form both in the absence and in the presence of water. The peak of $\mathrm{Pd}(\mathrm{OH})_{2}$ was not detected at 337.4 $\mathrm{eV}^{61}$ when water was co-fed, which indicates that bulk palladium hydroxide is not the cause of water inhibition effect over palladium foil. Notably, the percentage of hydroxyls increases considerably when water is co-dosed with the reaction mixture, mostly at the expense of surface $\mathrm{PdO}_{x}$. The presence of water in the feed converts dominantly the surface $\mathrm{PdO}_{x}$ into palladium hydroxyls, as shown in Figure 3 and Table 2 . This also indicates that the active sites for methane activation are on surface $\mathrm{PdO}_{\mathrm{x}}$. More specifically, coordinatively unsaturated palladium (hereafter called $\mathrm{Pd}_{\text {cus }}$ ) sites are contained in the polycrystalline surface $\mathrm{PdO}_{x}$ spectral component, and their role in the mechanism of methane combustion is confirmed in several literature reports ${ }^{14,}$ 58, 62-63. 
As already mentioned in the introduction, Fujimoto et al. ${ }^{14}$ proposed a sequence of reaction pathways in which the catalytic sites are coordinatively unsaturated palladium atoms and oxygen vacancies on the surface of PdO crystallites. Gaseous methane first binds to the $\mathrm{Pd}_{\text {cus }}$ sites, then hydrogen atoms are gradually abstracted by the adjacent surface $\mathrm{Pd}-\mathrm{O}$ sites and yield $\mathrm{Pd}-\mathrm{OH}$. Water is generated by the quasi-equilibrated condensation of surface hydroxyls and its desorption generates oxygen vacancies (hereafter called $\mathrm{O}_{\mathrm{v}}$ ). In this case, water favors the reverse reaction of hydroxyl recombination (i.e. palladium hydroxyl generation), described as:

$\mathrm{H}_{2} \mathrm{O}+\mathrm{Pd}-\mathrm{O}+\mathrm{Pd}-\mathrm{O}_{\mathrm{v}} \rightleftharpoons 2 \mathrm{Pd}-\mathrm{OH}$

Stotz et al. ${ }^{58}$ proposed another reaction route envisaging $\mathrm{H}$-abstraction from $\mathrm{Pd}-\mathrm{CH}_{2} \mathrm{O}$ that generates water. This step also generates carbon intermediates and releases $P d_{\text {cus }}$ sites, and can be described as:

$\mathrm{Pd}-\mathrm{CHOH}+\mathrm{Pd}-\mathrm{OH} \rightleftharpoons \mathrm{H}_{2} \mathrm{O}+\mathrm{Pd}-\mathrm{CHO}+\mathrm{Pd}_{\text {cus }}$

Based on the literature reports shown above, methane adsorption requires coordinatively unsaturated palladium sites $\left(\mathrm{Pd}_{\text {cus }}\right)$, while adjacent oxidic sites $(\mathrm{Pd}-\mathrm{O})$ are necessary to abstract the hydrogen forming hydroxyl groups. Notably, the inhibition of $\mathrm{Pd}_{\text {cus }}$ sites indicates that water competes with methane for the same adsorption sites. Water adsorbs on the $\mathrm{Pd}_{\text {cus }}$ sites and is then deprotonated by adjacent surface $\mathrm{Pd}-\mathrm{O}$ sites forming surface hydroxyls. As a consequence of this, the $\mathrm{H}$-abstraction process of methyl intermediates does not take place. The reaction (2) and reverse reaction (3) explain the negative order in water ${ }^{14}$ in the rate equation (1), which we experimentally correlate with the formation of surface palladium hydroxyls. Our study shows that the fraction of surface $\mathrm{PdO}_{\mathrm{x}}$ reaches its maximum in a limited 
temperature range, which is between 100 and $200^{\circ} \mathrm{C}$ for the $1: 2$ and $1: 4 \mathrm{CH}_{4}: \mathrm{O}_{2}$ reaction mixtures and extends to $300^{\circ} \mathrm{C}$ both in pure oxygen and when water is co-dosed. A decrease of the fraction of surface $\mathrm{PdO}_{\mathrm{x}}$ corresponds to the increase of the $\mathrm{PdO}$ population. Therefore, surface $\mathrm{PdO}_{\mathrm{x}}$ acts as a precursor of the bulk $\mathrm{PdO}$, as also confirmed by the correlation of the time-evolution of the surface $\mathrm{PdO}_{\mathrm{x}}$ component with that of $\mathrm{PdO}$ (Figure 5 and Table 2). Interestingly, the intensity of the surface $\mathrm{PdO}_{x}$ component evaluated from the $\mathrm{Pd} 3 \mathrm{~d}_{5 / 2}$ is not reaching zero in the temperature range where $\mathrm{PdO}$ is stable (Figure 2). This is due to two reasons:

i) Patches of surface $\mathrm{PdO}_{x}$ are stable at high temperatures, as shown when pure oxygen is dosed on palladium foil, thus no source of hydrogen is present ${ }^{64}$ (see Figure 2(c)).

ii) Hydroxyl groups are formed during the methane oxidation reaction. The photoemission peak associated with surface $\mathrm{Pd}-\mathrm{OH}$ and the one of surface $\mathrm{PdO}_{x}$ are superimposed in the $\mathrm{Pd} 3 \mathrm{~d}$ spectral region ${ }^{60}$. Therefore, the $335.6 \mathrm{eV}$ signal detected at $\mathrm{T}>200^{\circ} \mathrm{C}$ is also due to $\mathrm{Pd}-\mathrm{OH}$ formed during hydrogen abstraction form methane, as clearly seen in Figure $1 b$ and Figure $3 b$, without dosing water.

Because in our deconvolution of the Pd $3 d$ we made use of a single peak to fit the surface $\mathrm{PdO}_{x}$, we would like to stress that such a component contains three different kind of palladium surface oxide sites, and namely 2-coordinated palladium, 4-coordinated palladium and palladium hydroxy ${ }^{56,60,65}$.Therefore, water inhibition could affect $\mathrm{Pd}_{\text {cus }}$ as well as surface oxygen vacancies. For instance, the adsorption of water was recently observed on $\mathrm{Pd} / \mathrm{ZrO}_{2}$ catalyst ${ }^{66}$. Transformation of $\mathrm{t}-\mathrm{ZrO}_{2}$ to $\mathrm{m}-\mathrm{ZrO}_{2}$ forms oxygen vacancies and water weakens the 
promotion effect by the blocking of vacancy sites. The migration of oxygen vacancies is important in the reduction and oxidation process of palladium ${ }^{67}$.

As shown in Figure 2 and listed in Table 3, during our in situ steady state and transient measurements, we observed the concurrent postponement in PdO formation and a shift of the maximum palladium oxide initial formation rate in the presence of water, respectively. The temperature delay is $100^{\circ} \mathrm{C}$, which correlates well with the methane combustion reactivity tests on palladium catalysts ${ }^{24}, 60$. Typically, when water is added to the reaction mixture, a positive shift $\left(35-120^{\circ} \mathrm{C}\right.$ temperature range) of $\mathrm{T}_{50}$ (temperature at which $50 \%$ methane conversion is achieved) is measured ${ }^{25,68}$. The turnover rate for methane oxidation was found to decrease by $95 \%$ when PdO decomposed to Pd metal at $888 \mathrm{~K}$, showing that $\mathrm{PdO}$ is more active than $\mathrm{Pd}$ metal for methane combustion at this temperature ${ }^{69}$. The $\mathrm{Pd}-\mathrm{O}$ site is always considered as the activation site of methane, however, no agreement has been reached on whether PdO is the site of oxygen activation. In the traditional Mars-van-Krevelen redox mechanism for methane oxidation, the oxygen vacancies are always healed by gaseous oxygen ${ }^{14,58}$. Other reports claimed that the vacancy is filled by bulk PdO when the oxygen partial pressure above the catalyst is low, otherwise the oxygen vacancy will adsorb oxygen from the gas phase ${ }^{70}$. Experiments carried out making use of isotopically labeled reaction mixtures gave more details about the oxygen distribution in the reaction products, i.e. in water. At $600 \mathrm{~K}$, the oxygen in $\mathrm{H}_{2} \mathrm{O}$ is entirely coming from the PdO lattice. Burch ${ }^{21}$ also reported that oxygen chemisorbed on palladium metal is poorly active and that the methane conversion curve increases simultaneously to reach a plateau at the point where Pd has taken up about the equivalent of 3 monolayers of oxygen. Importantly, no further increase (or decrease) in the activity of the catalyst was observed after bulk PdO was formed. Martin et 
al. found that the efficiency of the methane oxidation reaction was strongly promoted by the presence of an oxygen atom directly underneath the $\mathrm{Pd}_{\text {cus }}$ atom in the $\mathrm{PdO}(101)$ structure with a ligand effect. The role of the oxygen atom is to induce a reduction of the Pauli repulsion between the $\mathrm{Pd}_{\text {cus }}$ and the $\mathrm{CH}_{4}$ molecule, which facilitates the $\mathrm{C}-\mathrm{H}$ bond activation. Therefore, bulk PdO can be considered an important active phase for the methane oxidation, because of providing oxygen and/or ligand effect. Based on these results, we can correlate the postponement in the formation of PdO observed in this study in the presence of water to the shift of the methane conversion curve observed experimentally on methane oxidation catalysts.

Table 3. Initial formation rate of $\mathrm{PdO}$ and surface $\mathrm{PdO}_{\mathrm{x}}$ with water on/off at different temperatures

\begin{tabular}{ccccc}
\hline \multirow{2}{*}{ Temperature $/{ }^{\circ} \mathrm{C}$} & \multicolumn{2}{c}{ Initial formation rate of PdO[a.u.] } & \multicolumn{2}{c}{ Initial formation rate of surface $\mathrm{PdO}_{\mathrm{x}}[\mathrm{a} . \mathrm{u}]}$. \\
& With water & Without water & With water & Without water \\
\hline 200 & 0.00094 & 0 & 0.0019 & 0.0056 \\
350 & 0.0016 & 0.0070 & 0.0037 & 0.014 \\
450 & 0.018 & 0.0016 & 0.018 & 0.0035 \\
600 & 0.0013 & 0 & 0.0025 & 0 \\
\hline
\end{tabular}

Such a shift is due to the inhibition of oxygen vacancies by water. As the XPS results show and as reported in references ${ }^{65,67,71}$, the surface $\mathrm{PdO}_{\mathrm{x}}$ is the precursor of PdO. The bulk-surface oxygen exchange requires the migration of oxygen vacancies. This step is described as:

$\mathrm{Pd}-\mathrm{O}($ surface $)+\mathrm{Pd}($ bulk $) \rightleftharpoons \mathrm{PdO}($ bulk $)+\mathrm{Pd}-\mathrm{O}_{\mathrm{v}}$

In the oxidation process, the vacancies are healed by gaseous oxygen. When water is co-dosed with the reagents, surface hydroxyls form and block the oxygen vacancies, thus the migration of oxygen. Consequently, PdO formation is delayed. Finally, upon recombination of $\mathrm{Pd}-\mathrm{OH}$ and water desorption, oxygen from the gas phase can react efficiently with the surface and 
the formation of a thicker PdO layer starts by the migration of oxygen between bulk and surface. Because PdO contributes to the methane oxidation reaction healing the oxygen vacancies left after $\mathrm{Pd}-\mathrm{OH}$ recombination, this effect may contribute to the water-mediated inhibition of the catalyst. 


\section{Conclusions}

Ambient pressure X-ray photoelectron spectroscopy was used to investigate in situ the palladium electronic states in the complete oxidation of methane on a palladium foil, and the effect of water co-dosing. The evolution of $\mathrm{Pd}(0)$, of surface $\mathrm{PdO}_{x}$ and of $\mathrm{PdO}$ were followed at different temperatures and under different gas environments. The main conclusions are:

1. Water inhibits the methane combustion reaction by converting surface palladium oxide to surface hydroxyls. Palladium hydroxyls block the coordinatively unsaturated palladium sites for methane adsorption and adjacent oxidic sites for methane activation. The hydrogenabstraction process of methyl reaction intermediates is also inhibited. Palladium hydroxide formation is not the consequence of water inhibition effect over palladium catalysts for the combustion of methane on palladium foil.

2. Water adsorbs on surface oxygen vacancies, followed by its deprotonation and the formation of a second hydroxyl on a neighboring $\mathrm{Pd}-\mathrm{O}$ site. The formation of a relevant amount of surface palladium hydroxyls in the presence of water hinders the adsorption of oxygen from the gas phase, postponing the formation of bulk PdO. Consequently, in the presence of water, the oxygen vacancy sites cannot be filled by oxygen migration from the bulk, and this effect contributes to the water inhibition effect on the combustion of methane. 


\section{Author information}

Corresponding authors

*E-mail: luca.artiglia@psi.ch.

*E-mail: jeroen.vanbokhoven@chem.ethz.ch

Notes

The authors declare no competing financial interest.

\section{Acknowledgments}

X.L. and X.W. acknowledge financial support from the China Scholarship Council. 


\section{References}

1. Chu, S.; Majumdar, A., Opportunities and challenges for a sustainable energy future. Nature 2012, 488, 294.

2. Zhu, G.; Han, J.; Zemlyanov, D. Y.; Ribeiro, F. H., The Turnover Rate for the Catalytic Combustion of Methane over Palladium Is Not Sensitive to the Structure of the Catalyst. J. Am. Chem. Soc. 2004, 126 (32), 9896-9897.

3. Lv, C.-Q.; Ling, K.-C.; Wang, G.-C., Methane combustion on Pd-based model catalysts: Structure sensitive or insensitive? The Journal of chemical physics 2009, 131 (14), 144704.

4. Stettler, M. E. J.; Midgley, W. J. B.; Swanson, J. J.; Cebon, D.; Boies, A. M., Greenhouse Gas and Noxious Emissions from Dual Fuel Diesel and Natural Gas Heavy Goods Vehicles. Environmental Science \& Technology 2016, 50 (4), 2018-2026.

5. Liu, Z.-P.; Hu, P., General Rules for Predicting Where a Catalytic Reaction Should Occur on Metal Surfaces: A Density Functional Theory Study of C-H and C-O Bond Breaking/Making on Flat, Stepped, and Kinked Metal Surfaces. J. Am. Chem. Soc. 2003, 125 (7), 1958-1967.

6. Gélin, P.; Primet, M., Complete oxidation of methane at low temperature over noble metal based catalysts: a review. Applied Catalysis B: Environmental 2002, 39 (1), 1-37.

7. Farrauto, R. J.; Hobson, M.; Kennelly, T.; Waterman, E., Catalytic chemistry of supported palladium for combustion of methane. Applied Catalysis A: General 1992, 81 (2), 227-237.

8. Burch, R.; Urbano, F. J.; Loader, P. K., Methane combustion over palladium catalysts: The effect of carbon dioxide and water on activity. Applied Catalysis A: General 1995, 123 (1), 173-184.

9. Zhu, G.; Han, J.; Zemlyanov, D. Y.; Ribeiro, F. H., Temperature dependence of the kinetics for the complete oxidation of methane on palladium and palladium oxide. The Journal of Physical Chemistry B 2005, 109 (6), 2331-2337.

10. Persson, K.; Pfefferle, L. D.; Schwartz, W.; Ersson, A.; Järås, S. G., Stability of palladium-based catalysts during catalytic combustion of methane: The influence of water. Applied Catalysis $B$ : Environmental 2007, 74 (3), 242-250.

11. Cargnello, M.; Jaén, J. J. D.; Garrido, J. C. H.; Bakhmutsky, K.; Montini, T.; Gámez, J. J. C.; Gorte, R. J.; Fornasiero, P., Exceptional Activity for Methane Combustion over Modular Pd@CeO units on Functionalized $\mathrm{Al}_{2} \mathrm{O}_{3}$. Science 2012, 337 (6095), 713-717.

12. Cullis, C. F.; Nevell, T. G.; Trimm, D. L., Role of the catalyst support in the oxidation of methane over palladium. Journal of the Chemical Society, Faraday Transactions 1: Physical Chemistry in Condensed Phases 1972, 68 (0), 1406-1412.

13. Ribeiro, F. H.; Chow, M.; Dallabetta, R. A., Kinetics of the Complete Oxidation of Methane over Supported Palladium Catalysts. Journal of Catalysis 1994, 146 (2), 537-544.

14. Fujimoto, K.-i.; Ribeiro, F. H.; Avalos-Borja, M.; Iglesia, E., Structure and Reactivity of $\mathrm{PdO}_{\mathrm{x}} / \mathrm{ZrO}_{2}$ Catalysts for Methane Oxidation at Low Temperatures. Journal of Catalysis 1998, 179 (2), 431-442.

15. Hoflund, G. B.; Hagelin, H. A. E.; Weaver, J. F.; Salaita, G. N., ELS and XPS study of Pd/PdO methane oxidation catalysts. Applied Surface Science 2003, 205 (1), 102-112.

16. Han, J.; Zemlyanov, D. Y.; Ribeiro, F. H., Catalytic combustion of methane on palladium single crystals. Catalysis Today 2006, 117 (4), 506-513.

17. Meng, L.; Lin, J.-J.; Pu, Z.-Y.; Luo, L.-F.; Jia, A.-P.; Huang, W.-X.; Luo, M.-F.; Lu, J.-Q., Identification of active sites for $\mathrm{CO}$ and $\mathrm{CH}_{4}$ oxidation over $\mathrm{PdO} / \mathrm{Ce}_{1-\mathrm{x}} \mathrm{Pd}_{x} \mathrm{O}_{2-\delta}$ catalysts. Applied Catalysis B: Environmental 2012, 119-120, 117-122.

18. Bossche, M. V. d.; Grönbeck, H., Methane Oxidation over PdO(101) Revealed by FirstPrinciples Kinetic Modeling. J. Am. Chem. Soc. 2015, 137 (37), 12035-12044.

19. Colussi, S.; Gayen, A.; Farnesi Camellone, M.; Boaro, M.; Llorca, J.; Fabris, S.; Trovarelli, A., Nanofaceted Pd-O Sites in Pd-Ce Surface Superstructures: Enhanced Activity in Catalytic Combustion of Methane. Angewandte Chemie International Edition 2009, 48 (45), 8481-8484. 
20. Willis, J. J.; Gallo, A.; Sokaras, D.; Aljama, H.; Nowak, S. H.; Goodman, E. D.; Wu, L.; Tassone, C. J.; Jaramillo, T. F.; Abild-Pedersen, F.; Cargnello, M., Systematic Structure-Property Relationship Studies in Palladium-Catalyzed Methane Complete Combustion. ACS Catal. 2017, 7 (11), 7810-7821. 21. Burch, R., Low $\mathrm{NO}_{x}$ options in catalytic combustion and emission control. Catalysis Today 1997, 35 (1), 27-36.

22. Duan, H.; You, R.; Xu, S.; Li, Z.; Qian, K.; Cao, T.; Huang, W.; Bao, X., Pentacoordinated $\mathrm{Al}^{3+}$ Stabilized Active Pd Structures on $\mathrm{Al}_{2} \mathrm{O}_{3}$-Coated Palladium Catalysts for Methane Combustion. Angewandte Chemie International Edition 2019, 58 (35), 12043-12048.

23. Monteiro, R. S.; Zemlyanov, D.; Storey, J. M.; Ribeiro, F. H., Turnover Rate and Reaction Orders for the Complete Oxidation of Methane on a Palladium Foil in Excess Dioxygen. Journal of Catalysis 2001, 199 (2), 291-301.

24. Zhang, F.; Hakanoglu, C.; Hinojosa, J. A.; Weaver, J. F., Inhibition of methane adsorption on $\mathrm{PdO}(101)$ by water and molecular oxygen. Surface Science 2013, 617, 249-255.

25. Petrov, A. W.; Ferri, D.; Krumeich, F.; Nachtegaal, M.; van Bokhoven, J. A.; Kröcher, O., Stable complete methane oxidation over palladium based zeolite catalysts. Nature Communications 2018, 9 (1), 2545.

26. Schwartz, W. R.; Ciuparu, D.; Pfefferle, L. D., Combustion of Methane over Palladium-Based Catalysts: Catalytic Deactivation and Role of the Support. The Journal of Physical Chemistry C 2012, 116 (15), 8587-8593.

27. Barrett, W.; Shen, J.; Hu, Y.; Hayes, R. E.; Scott, R. W. J.; Semagina, N., Understanding the Role of $\mathrm{SnO}_{2}$ Support in Water-Wolerant Methane Combustion: In situ Observation of $\mathrm{Pd}(\mathrm{OH})_{2}$ and Comparison with $\mathrm{Pd} / \mathrm{Al}_{2} \mathrm{O}_{3}$. ChemCatChem 2020, 12 (3), 944-952.

28. Toso, A.; Colussi, S.; Llorca, J.; Trovarelli, A., The dynamics of PdO-Pd phase transformation in the presence of water over Si-doped $\mathrm{Pd} / \mathrm{CeO}_{2}$ methane oxidation catalysts. Applied Catalysis A: General 2019, 574, 79-86.

29. Gholami, R.; Smith, K. J., Activity of $\mathrm{PdO} / \mathrm{SiO}_{2}$ catalysts for $\mathrm{CH}_{4}$ oxidation following thermal treatments. Applied Catalysis B: Environmental 2015, 168-169, 156-163.

30. Lustemberg, P. G.; Palomino, R. M.; Gutiérrez, R. A.; Grinter, D. C.; Vorokhta, M.; Liu, Z.; Ramírez, P. J.; Matolín, V.; Ganduglia-Pirovano, M. V.; Senanayake, S. D.; Rodriguez, J. A., Direct Conversion of Methane to Methanol on Ni-Ceria Surfaces: Metal-Support Interactions and WaterEnabled Catalytic Conversion by Site Blocking. J. Am. Chem. Soc. 2018, 140 (24), 7681-7687.

31. Velin, P.; Ek, M.; Skoglundh, M.; Schaefer, A.; Raj, A.; Thompsett, D.; Smedler, G.; Carlsson, P.-A., Water Inhibition in Methane Oxidation over Alumina Supported Palladium Catalysts. The Journal of Physical Chemistry C 2019, 123 (42), 25724-25737.

32. Huang, W.; Goodman, E. D.; Losch, P.; Cargnello, M., Deconvoluting Transient Water Effects on the Activity of Pd Methane Combustion Catalysts. Industrial \& Engineering Chemistry Research 2018, 57 (31), 10261-10268.

33. Gremminger, A. T.; Pereira de Carvalho, H. W.; Popescu, R.; Grunwaldt, J.-D.; Deutschmann, $\mathrm{O}$., Influence of gas composition on activity and durability of bimetallic $\mathrm{Pd}-\mathrm{Pt} / \mathrm{Al}_{2} \mathrm{O}_{3}$ catalysts for total oxidation of methane. Catalysis Today 2015, 258, 470-480.

34. Nassiri, H.; Lee, K.-E.; Hu, Y.; Hayes, R. E.; Scott, R. W. J.; Semagina, N., Water shifts PdOcatalyzed lean methane combustion to Pt-catalyzed rich combustion in Pd-Pt catalysts: In situ X-ray absorption spectroscopy. Journal of Catalysis 2017, 352, 649-656.

35. Ersson, A.; Kušar, H.; Carroni, R.; Griffin, T.; Järås, S., Catalytic combustion of methane over bimetallic catalysts a comparison between a novel annular reactor and a high-pressure reactor. Catalysis Today 2003, 83 (1), 265-277.

36. Alyani, M.; Smith, K. J., Kinetic Analysis of the Inhibition of $\mathrm{CH}_{4}$ Oxidation by $\mathrm{H}_{2} \mathrm{O}$ on $\mathrm{PdO} / \mathrm{Al}_{2} \mathrm{O}_{3}$ and $\mathrm{CeO}_{2} / \mathrm{PdO} / \mathrm{Al}_{2} \mathrm{O}_{3}$ Catalysts. Industrial \& Engineering Chemistry Research 2016, 55 (30), 8309-8318.

37. Monteiro, R. S.; Zemlyanov, D.; Storey, J. M.; Ribeiro, F. H., Surface Area Increase on Pd Foils after Oxidation in Excess Methane. Journal of Catalysis 2001, 201 (1), 37-45. 
38. Weckhuysen, B. M., Snapshots of a working catalyst: possibilities and limitations of in situ spectroscopy in the field of heterogeneous catalysis. Chemical Communications 2002, (2), 97-110. 39. Rodríguez, J. A.; Hanson, J. C.; Chupas, P. J., In-situ characterization of heterogeneous catalysts. Wiley Online Library: 2013; Vol. 1.

40. Li, X.; Yang, X.; Zhang, J.; Huang, Y.; Liu, B., In Situ/Operando Techniques for Characterization of Single-Atom Catalysts. ACS Catal. 2019, 9 (3), 2521-2531.

41. Karslıoğlu, O.; Bluhm, H., Ambient-Pressure X-ray Photoelectron Spectroscopy (APXPS). In Operando Research in Heterogeneous Catalysis, Frenken, J.; Groot, I., Eds. Springer International Publishing: Cham, 2017; pp 31-57.

42. Roy, K.; Artiglia, L.; van Bokhoven, J. A., Ambient Pressure Photoelectron Spectroscopy: Opportunities in Catalysis from Solids to Liquids and Introducing Time Resolution. ChemCatChem 2018, 10 (4), 666-682.

43. Artiglia, L.; Orlando, F.; Roy, K.; Kopelent, R.; Safonova, O.; Nachtegaal, M.; Huthwelker, T.; van Bokhoven, J. A., Introducing Time Resolution to Detect $\mathrm{Ce}^{3+}$ Catalytically Active Sites at the $\mathrm{Pt} / \mathrm{CeO}_{2}$ Interface through Ambient Pressure X-ray Photoelectron Spectroscopy. The Journal of Physical Chemistry Letters 2017, 8 (1), 102-108.

44. Artiglia, L.; Sushkevich, V. L.; Palagin, D.; Knorpp, A. J.; Roy, K.; van Bokhoven, J. A., In Situ Xray Photoelectron Spectroscopy Detects Multiple Active Sites Involved in the Selective Anaerobic Oxidation of Methane in Copper-Exchanged Zeolites. ACS Catal. 2019, 9 (8), 6728-6737.

45. Ammann, M.; Artiglia, L.; Bartels-Rausch, T., Chapter 6 - X-Ray Excited Electron Spectroscopy to Study Gas-Liquid Interfaces of Atmospheric Relevance. In Physical Chemistry of Gas-Liquid Interfaces, Faust, J. A.; House, J. E., Eds. Elsevier: 2018; pp 135-166.

46. Artiglia, L.; Edebeli, J.; Orlando, F.; Chen, S.; Lee, M.-T.; Corral Arroyo, P.; Gilgen, A.; BartelsRausch, T.; Kleibert, A.; Vazdar, M.; Andres Carignano, M.; Francisco, J. S.; Shepson, P. B.; Gladich, I.; Ammann, M., A surface-stabilized ozonide triggers bromide oxidation at the aqueous solutionvapour interface. Nature Communications 2017, 8 (1), 700.

47. Orlando, F.; Waldner, A.; Bartels-Rausch, T.; Birrer, M.; Kato, S.; Lee, M.-T.; Proff, C.; Huthwelker, T.; Kleibert, A.; van Bokhoven, J.; Ammann, M., The Environmental Photochemistry of Oxide Surfaces and the Nature of Frozen Salt Solutions: A New in Situ XPS Approach. Topics in Catalysis 2016, 59 (5), 591-604.

48. Doniach, S.; Sunjic, M., Many-electron singularity in X-ray photoemission and X-ray line spectra from metals. Journal of Physics C: Solid State Physics 1970, 3 (2), 285.

49. Teschner, D.; Pestryakov, A.; Kleimenov, E.; Hävecker, M.; Bluhm, H.; Sauer, H.; KnopGericke, A.; Schlögl, R., High-pressure X-ray photoelectron spectroscopy of palladium model hydrogenation catalysts.: Part 1: Effect of gas ambient and temperature. Journal of Catalysis 2005, 230 (1), 186-194.

50. Zemlyanov, D.; Aszalos-Kiss, B.; Kleimenov, E.; Teschner, D.; Zafeiratos, S.; Hävecker, M.; Knop-Gericke, A.; Schlögl, R.; Gabasch, H.; Unterberger, W., In situ XPS study of Pd (111) oxidation. Part 1: 2D oxide formation in $10^{-3} \mathrm{mbar}_{2}$. Surface science 2006, 600 (5), 983-994.

51. Ketteler, G.; Ogletree, D. F.; Bluhm, H.; Liu, H.; Hebenstreit, E. L. D.; Salmeron, M., In Situ Spectroscopic Study of the Oxidation and Reduction of Pd(111). J. Am. Chem. Soc. 2005, 127 (51), 18269-18273.

52. Toyoshima, R.; Yoshida, M.; Monya, Y.; Kousa, Y.; Suzuki, K.; Abe, H.; Mun, B. S.; Mase, K.; Amemiya, K.; Kondoh, H., In Situ Ambient Pressure XPS Study of CO Oxidation Reaction on Pd(111) Surfaces. The Journal of Physical Chemistry C 2012, 116 (35), 18691-18697.

53. Lundgren, E.; Kresse, G.; Klein, C.; Borg, M.; Andersen, J. N.; De Santis, M.; Gauthier, Y.; Konvicka, C.; Schmid, M.; Varga, P., Two-Dimensional Oxide on Pd(111). Physical Review Letters 2002, 88 (24), 246103.

54. Todorova, M.; Lundgren, E.; Blum, V.; Mikkelsen, A.; Gray, S.; Gustafson, J.; Borg, M.; Rogal, J.; Reuter, K.; Andersen, J. N.; Scheffler, M., The Pd(100) - $(\sqrt{ } 5 \times \sqrt{ } 5) R 27^{\circ}-O$ surface oxide revisited. Surface Science 2003, 541 (1), 101-112. 
55. Titkov, A. I.; Salanov, A. N.; Koscheev, S. V.; Boronin, A. I., Mechanisms of Pd(110) surface reconstruction and oxidation: XPS, LEED and TDS study. Surface Science 2006, 600 (18), 4119-4125.

56. Kibis, L. S.; Titkov, A. I.; Stadnichenko, A. I.; Koscheev, S. V.; Boronin, A. I., X-ray photoelectron spectroscopy study of Pd oxidation by RF discharge in oxygen. Applied Surface Science 2009, 255 (22), 9248-9254.

57. Joska, L.; Marek, M.; Leitner, J., The mechanism of corrosion of palladium-silver binary alloys in artificial saliva. Biomaterials 2005, 26 (14), 1605-1611.

58. Stotz, H.; Maier, L.; Boubnov, A.; Gremminger, A. T.; Grunwaldt, J. D.; Deutschmann, O., Surface reaction kinetics of methane oxidation over PdO. Journal of Catalysis 2019, 370, 152-175.

59. Tsukada, C.; Ogawa, S.; Niwa, H.; Nomoto, T.; Kutluk, G.; Namatame, H.; Taniguchi, M.; Yagi, S., Morphological and spectroscopic studies on enlargement of $\mathrm{Pd}$ nanoparticle in I-cysteine aqueous solution by AFM and XPS. Applied Surface Science 2013, 267, 48-52.

60. Gladys, M. J.; El Zein, A. A.; Mikkelsen, A.; Andersen, J. N.; Held, G., Chemical composition and reactivity of water on clean and oxygen-covered Pd\{111\}. Surface Science 2008, 602 (22), 35403549.

61. Khudorozhkov, A. K.; Chetyrin, I. A.; Bukhtiyarov, A. V.; Prosvirin, I. P.; Bukhtiyarov, V. I., Propane Oxidation Over Pd/Al $\mathrm{O}_{3}$ : Kinetic and In Situ XPS Study. Topics in Catalysis 2017, 60 (1), 190197.

62. Su, Y.-Q.; Liu, J.-X.; Filot, I. A. W.; Zhang, L.; Hensen, E. J. M., Highly Active and Stable $\mathrm{CH}_{4}$ Oxidation by Substitution of $\mathrm{Ce}^{4+}$ by Two $\mathrm{Pd}^{2+}$ Ions in $\mathrm{CeO}_{2}$ (111). ACS Catal. 2018, 8 (7), 6552-6559.

63. Hellman, A.; Resta, A.; Martin, N. M.; Gustafson, J.; Trinchero, A.; Carlsson, P. A.; Balmes, O.; Felici, R.; van Rijn, R.; Frenken, J. W. M.; Andersen, J. N.; Lundgren, E.; Grönbeck, H., The Active Phase of Palladium during Methane Oxidation. The Journal of Physical Chemistry Letters 2012, 3 (6), 678-682.

64. Rogal, J.; Reuter, K.; Scheffler, M., Thermodynamic stability of PdO surfaces. Physical Review B 2004, 69 (7), 075421.

65. Westerström, R.; Messing, M. E.; Blomberg, S.; Hellman, A.; Grönbeck, H.; Gustafson, J.; Martin, N. M.; Balmes, O.; van Rijn, R.; Andersen, J. N.; Deppert, K.; Bluhm, H.; Liu, Z.; Grass, M. E.; Hävecker, M.; Lundgren, E., Oxidation and reduction of $\mathrm{Pd}(100)$ and aerosol-deposited $\mathrm{Pd}$ nanoparticles. Physical Review B 2011, 83 (11), 115440.

66. Wu, Y.; Chen, J.; Hu, W.; Zhao, K.; Qu, P.; Shen, P.; Zhao, M.; Zhong, L.; Chen, Y., Phase transformation and oxygen vacancies in $\mathrm{Pd} / \mathrm{ZrO}_{2}$ for complete methane oxidation under lean conditions. Journal of Catalysis 2019, 377, 565-576.

67. Wolf, M. M.; Zhu, H.; Green, W. H.; Jackson, G. S., Kinetic model for polycrystalline Pd/PdO in oxidation/reduction cycles. Applied Catalysis A: General 2003, 244 (2), 323-340.

68. Mihai, O.; Smedler, G.; Nylén, U.; Olofsson, M.; Olsson, L., The effect of water on methane oxidation over $\mathrm{Pd} / \mathrm{Al}_{2} \mathrm{O}_{3}$ under lean, stoichiometric and rich conditions. Catalysis Science \& Technology 2017, 7 (14), 3084-3096.

69. Zhu, G., Kinetics of Complete Methane Oxidation on Palladium Model Catalysts. Worcester Polytechnic Institute 2004, DOCTORAL DISSERTATION.

70. Ciuparu, D.; Altman, E.; Pfefferle, L., Contributions of Lattice Oxygen in Methane Combustion over PdO-Based Catalysts. Journal of Catalysis 2001, 203 (1), 64-74.

71. Martin, N. M.; Van den Bossche, M.; Hellman, A.; Grönbeck, H.; Hakanoglu, C.; Gustafson, J.; Blomberg, S.; Johansson, N.; Liu, Z.; Axnanda, S.; Weaver, J. F.; Lundgren, E., Intrinsic Ligand Effect Governing the Catalytic Activity of Pd Oxide Thin Films. ACS Catal. 2014, 4 (10), 3330-3334. 


\section{Abstract Graphics}

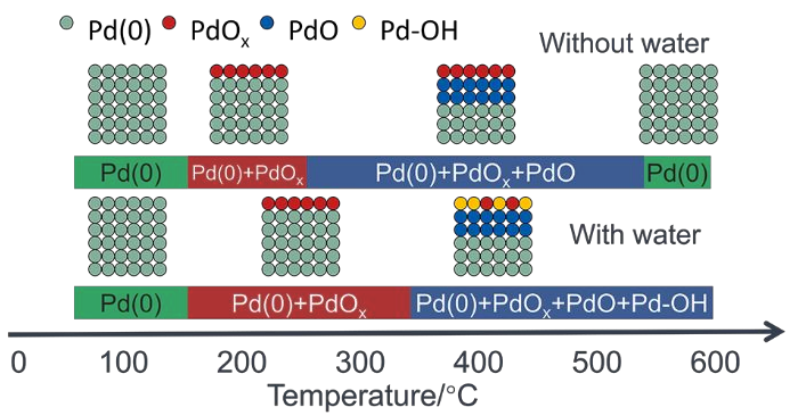

